in other biological sub-disciplines. The physiologist may find unexplored vistas of research in fish parasites; the zoogeographer can find examples of an additional, possibly powerful, tool in the form of fish parasites; and the population biologist may see an added dimension to his studies of free-living animals.

Cari J. Sindermann

\section{INTRODUCTION TO PLANT GROWTH}

The Control of Growth and Differentiation in Plants By P. F. Wareing and I. D. J. Phillips. (The Commonwealth and International Library of Science, Technology, Engineering and Liberal Studies: Botany Division.) Pp. $x+303$. (Pergamon: Oxford and New York, May 1970.) $50 s(\$ 7)$ board; $40 s(\$ 5.50)$ flexi-cover.

THIs widely ranging book is chiefly intended as an introduction to plant growth and development for undergraduate students. As its title suggests, its emphasis is on control, and particular attention is given to the role of natural regulators of growth and differentiation processes. The first three chapters describe the characteristics of cell growth and differentiation, and show how they are related to the morphogenesis of tissue and organisms. Then follow four chapters on the nature of plant growth hormones and their respective roles in the growth of stem and root, including secondary growth, in bud and fruit growth and in abscission. Hormones and growth movements occupy one chapter and a short chapter is included on the sterile culture of cells and organs. Two long chapters outline the complexities of the physiology of flowering and there are two excellent chapters on dormancy and senescence respectively. A final chapter summarizes in simple terms current modern ideas on the genetic aspects of development control. Each chapter ends with a list of about a dozen review articles for further reading.

This bcok should serve as an excellent textbook for undergraduates taking basic courses in plant physiology. More advanced undergraduates specializing in this area will find it a useful guide to further review articles in this field. They may, however, also find rather distressing, as I did, the deliberate omission of supporting evidence for all but a few statements, and a complete lack of reference to individual pieces of research work. Admittedly the over-larding of the text with authors' names and dates of publication does tend to interrupt the logical flow of an argument, but an important function of a textbook is to stimulate the student to read the important key research papers- to see for himself how fundamentel advances are made. This book should stimulate, but it will not help him to do this. The book is clearly but not overlavishly illustrated with carefully chosen diagrams and photographs. It has a pleasant format and suffers from very few errors (for example, the misnaming of Iunaria on pages 201 and 204).

L. J. AUDUs

\section{DISEASES OF ROOT SYSTEMS}

\section{Pathogenic Root-infecting Fungi}

By S. D. Garrett. Pp. xi+294. (Cambridge University: London, July 1970.) 75s; $\$ 12.50$.

THrs book is a sequel to Dr Garrett's Biology of Rootinfecting F ungi published in 1956. 'The very high standard. to which we are accustomed from all his previous publications is maintained. This work will be invaluable not only to the specialist but also to students of botany.
Although the author states that the book can be read through, and this is very true, it can certainly be used as a reference work because the bibliography is extensive and the subject matter is very comprehensive. The style of presentation is lucid and authoritative.

The author is not merely an academic mycologist/plant pathologist; he makes it clear that his studies are economically important as well as fundamental. Throughout the book he constantly brings home the important truth that "disesses of the root systems cannot be studied in isolation as a simple intersction between root system and fungal pathogen", and he stresses that an appreciation of what is going on in the soil is fundamental to an understanding of the disease.

In an excellent introductory chapter, problems are surveyed and definitions of terms are proposed. The discussion on inoculum-potential and the concept of "energy of growth" available in the fungus to cause infection is particularly interesting. Unspecialized parasites are discussed in the second chapter and this is followed by two chapters on the specialized parasites-one dealing with vascular wilt fungi and the other with ectotrophic root-infecting fungi. The saprophytic activities of these organisms are then considered under the headings of competitive saprophytic colonization of substrates and saprophytic survival in infected host tissues. Then follows an excellent survey of dormant survival by resting propagules, spores and sclerotia of these fungi. The last chapter deals very thoroughly with principles of control of root diseases of field crops, intensive crops and plantation crops.

There are twenty-five diagrams present as contrasted with their virtuel absence in Biology of Root-infecting Fungi. In this earlier book, Garrett stated that what is evident in the study of plant pathology "is a paradox of biology today; it is divided up as never before, yet never before, perhaps, has its unity seemed more apparent to us". In his new book he goes a long way to make the unity of plant pathology real; he has once again produced what may be termed a philosophy of plant pathology.

Pathogenic Root-infecting Fungi is a mine of information and has a very useful index. The production is excellent. It is most strongly recommended. IvOR IsAAC

\section{PHOTOSYNTHETIC RESEARCH, 1968}

\section{Progress in Photosynthesis Research}

Edited by Helmut Metzner. Vol. 1: Structure of the Photosynthetic Apparatus, Physiology of Photosynthesis. Pp. xv+1-536+37. Vol. 2: Plastid Pigments, Electron Transfer. Pp. xi+537-1128. Vol. 3: Photophosphorylation, $\mathrm{CO}_{2}$ Fixation, Action Mechanisms of Herbicides. Pp. 1129-1887+ 37. (Verlag C. Lichtenstein: Munich, 1969.) $35986 d$ the set.

THESE volumes contain the papers read at an international conference on photosynthesis. The book, like the conference, covers a wider range of photosynthetic research than any other recent symposium which deals with the topics at comparable depth. There are, howevor, notable gaps in its coverage of modern research. It would have been useful to have a paper on experiments with heavy oxygen in the section on photorespiration, along with the papers on tracer carbon and net gas exchange techniques. Another lacuna was the absence of a paper on the biochemistry of plants which fix $\mathrm{CO}_{2}$ by way of the $\mathbf{C}_{4}$ dicarboxylic acid pathway. Finally, the central dogma of photosynthesis, the "Z scheme" for non-cyclic photophosphorylation, was only attacked by Arnon. More severe criticisms of its basic tenets, such as Arnold with his solid state model, and the Warburg-VenneslandStiller view that interaction of $\mathrm{CO}_{2}$ with chlorophyll is the primary event, were not represented. I do not wish to 